hinzu, wobei man das Gefäß gut verschließt. Nach dem Erkalten gießt man vom abgeschiedenen Kaliumsulfat ab. Die Reaktion verläuft dabei nach folgender Gleichung:

$$
\begin{array}{r}
5 \mathrm{KBr}+\mathrm{KBrO}_{3}+3 \mathrm{H}_{2} \mathrm{SO}_{4}=6 \mathrm{Br}+3 \mathrm{H}_{2} \mathrm{O}+3 \mathrm{~K}_{2} \mathrm{SO}_{4} . \\
\text { W. Dehio. }
\end{array}
$$

Polarographische Prüfung von Äthyläther. B. A. Gosman ${ }^{1}$ ) hat die Reinheit von Athyläther auf polarographischem Wege geprüft. Äthyläther darf für narkotische Zwecke keinen Aldehyd und kein Peroxyd enthalten. Äther leitet den Strom praktisch nicht; deshalb werden die zu untersuchenden Proben mit einer 0,01 n-Lösung von Lithiumhydroxyd in Wasser ausgeschüttelt. Reiner Äther, der trocken und vor licht geschützt aufbewahrt wird, ergibt bei etwa 1,4 Volt eine kleine Welle, während diese bei unreinem Äther viel stärker ausgebildet ist. Außerdem zeigt Äther, der Oxydationsprodukte enthält, eine zweite Stufe bei 1,8 Volt. Weil bei dem erstgenannten Potential Wasserstoffperoxyd an der Quecksilbertropfelektrode reduziert wird, schreibt der Verfasser den ersten Anstieg der Stromstärke einem Vorgang zu, der dje Peroxydkomponente betrifft. Der zweite Sprung tritt beim Reduktionspotential des Acetaldehyds auf, das sich am besten in alkalischer Lösung zeigt. Neben diesem Vorteil bietet die angewendete Lithiumhydroxydlösung noch zwei weitere: Das wesentlich negativere Potential, bei dem Lithium entladen wird, und das gute Aufnahmevermögen für die saure Peroxydkomponente. Der polarographische Nachweis ist wesentlich empfindlicher als der chemische. Gosman hat sein Verfahren benutzt, um die Wirksamkeit der verschiedenen Reinigungsmethoden zu prüfen, und hat die besten Werte gefunden, wenn Äther über einer $10 \%$ igen Kalilauge 24 Stdn. steht und gelegentlich um. geschüttelt wird. Er hat ferner die Verteilung der Oxydationsprodukte zwischen der Äther- und der Laugenschicht bestimmt und zeigen können, daß der Gehalt an Peroxyd ab- und der an Aldehyd zunimmt, wenn der Äther mit Quecksilber geschüttelt wird. Damit werden die Theorien gestützt, die den Aldehyd aus dem Peroxyd entstehen lassen. Bei der Oxydation mit ozonisiertem Sauerstoff oder an einem rotglühenden Draht tritt Peroxyd als erstes Oxydationsprodukt auf. H. Hölemann.

4. Auf Physiologie und Pathologie bezügliche Methoden. Von

\title{
P. Haas.
}

Pflanzenphysiologisch-chemische und agrikulturchemische Mikromethoden. S. Prát ${ }^{2}$ ) prüft die Eignung bekannter Reagenzien für den histochemischen Nachweis von Schwermetallen in den Pflanzen. Blei. Frisch bereitetes Schwefelwasserstoffwasser ist ein besseres Fällungsreagens als Alkalisulfidlösung, aber seine Unbeständigkeit bildet einen Nachteil. Eine Lösung von 1 Teil 30\%iger Natrium-

1) Collect. Trav. chim. Tchécoslovaquie 7, 467 (1935). - 2) Mikrochemie, Molisch-Festschrift, S. 342 (1936). 